\title{
Effect of different self-etch adhesive application methods on the shear bond strengths of composite resin to dentin
}

\author{
BERNADETTE KEREKES-MATHE ${ }^{1}$, MELINDA SZEKELY ${ }^{1}$, ORSOLYA CSISZER ${ }^{2}$, \\ MELINDA KIS ${ }^{3}$, VANDA ROXANA NIMIGEAN ${ }^{4}$, VICTOR NIMIGEAN ${ }^{5}$, KINGA DORNER ${ }^{6}$ \\ "'George Emil Palade" University of Medicine, Pharmacy, Science and Technology of Targu Mures, Faculty \\ of Dental Medicine, Department of Morphology of Teeth and Dental Arches; Technology of Dental Prosthesis and \\ Dental Materials, 38 Gh. Marinescu Str., 540139, Targu Mures, Romania \\ ${ }^{2}$ Postgraduate student, "George Emil Palade" University of Medicine, Pharmacy, Science and Technology of Targu \\ Mures, Faculty of Dental Medicine, 38 Gh. Marinescu Str., 540139, Targu Mures, Romania \\ ${ }^{3}$ Private Dental Practice, Savinestilor Street 1, 410432, Oradea, Romania \\ ${ }^{4}$ Carol Davila University of Medicine and Pharmacy in Bucharest, Faculty of Dental Medicine, Department of Oral \\ Rehabilitation, 8 Eroilor Sanitari Str., 050474, Bucuresti, Romania \\ ${ }^{5}$ Carol Davila University of Medicine and Pharmacy in Bucharest, Faculty of Dental Medicine, Department of Anatomy, \\ 17-23 Calea Plevnei Str., 010221, Bucharest, Romania \\ "6"George Emil Palade” University of Medicine, Pharmacy, Science and Technology of Targu Mures, Faculty of Dental \\ Medicine, Department of Removable Prosthetic Dentistry, 38 Gh. Marinescu Str., 540139, Targu Mures, Romania
}

\begin{abstract}
Dental adhesion is a complex phenomenon that has challenged the conventional biomechanical principles applied to Dental Medicine. Many of the advances in aesthetic restorative dentistry are due to dental adhesion: bond of direct resin-based restorations, bond of all ceramic restorations, bond of orthodontic brackets, bond of indirect resin-based restorations and improving tooth shape and colour. An adhesive is a material that not only joins two substrates together, but also transfers loads from one surface to another. Therefore, the performance of dental adhesion is measured through adhesion strength. This paper aims at investigating the influence of application method and the optional preliminary acid etching on the shear bond strengths of a composite resin to dentin, using self-etch adhesives in single or double layer. Buccal surfaces of 40 extracted human teeth were prepared and dental adhesives were applied on the dentin surfaces. Microshear bond strength increased when double-layer application was used, but this improvement was adhesive dependent. The use of optional preliminary acid etching did not improve significantly the bond strength to dentin.
\end{abstract}

Keywords Dental adhesive, composite resin, dentin, bond strength, in vitro study.

To cite this article: KEREKES-MATHE B, SZEKELY M, CSISZER O, KIS M, NIMIGEAN VR, NIMIGEAN V, DORNER K. Effect of different self-etch adhesive application methods on the shear bond strengths of composite resin to dentin. Rom Biotechnol Lett. 2020; 25(6): 2188-2193. DOI: $10.25083 / \mathrm{rbl} / 25.6 / 2188.2193$

*Corresponding author: VANDA ROXANA NIMIGEAN, Associate Professor, Head of Oral Rehabilitation Department, Faculty of Dental Medicine, "Carol Davila" University of Medicine and Pharmacy, Bucharest, Romania, No 17-23 Calea Plevnei Street. Phone: +40721561848 E-mail: vandanimigean@yahoo.com

MELINDA SZEKELY, Professor, Head of Department of Morphology of Teeth and Dental Arches; Technology of Dental Prosthesis and Dental Materials, Faculty of Dental Medicine, "George Emil Palade" University of Medicine, Pharmacy, Science and Technology of Targu Mures, Romania, No 38 Gh. Marinescu Street, Phone: +40744878610. E-mail: melinda.szekely@umfst.ro 


\section{Introduction}

Composite resin materials are polymer-based direct filling materials which have undergone remarkable development in the last few decades. The clinical longevity of these materials has been increasing mainly due to improvements of adhesion to tooth structures. An adhesive system has to be selected to ensure that the composite resin is well bonded to the tooth structures. Different adhesive systems and application protocols are available and there are many possibilities for error during the procedure steps (C.S. PFEIFER [1]).

Therefore, bonding of resin-based composite materials is subject to continuous development. The bonding of composite restorative resins to tooth structures must be assured by using modern adhesive systems and appropriate techniques (A. BORS \& al [2]).

Adhesion to composite resin is achieved by copolymerisation, while adherence to the tooth surface is obtained by micromechanical retention. The chemical composition of adhesives should enable these mechanisms. Each adhesive system contains the acidic monomer ingredient, which has its role in demineralisation, regardless of its type or the method of application. The other chemical components also have a role in determining the bond strength, mild or strong adhesives (N.H. FELEMBAN and M.I. EBRAHIM [3], E.L. PASHLEY \& al [4]).

One of the factors influencing strengths of adhesion is moisture control. The wetness of the dentin surface may affect the bond strengths, depending on the adhesive system used (A.N. CHOI \& al [5]).

Another important factor is the adhesive's surface tension. Adhesive forces are maximized when the adhesive and the given surface are in close contact of the largest surface possible (J.F. MCCABE and A.W.G. WALLS [6]).

However, the quality of adhesion also depends on the tooth structure. In enamel, an appropriate demineralization provides the microretentions between the enamel prisms that can assure strong adhesion. In dentin the durable adhesion is more difficult to achieve because it relies on organic components (A.D. LOGUERCIO \& al [7]).

Less mineralized, collagen fibres contained by intertubular dentin can be observed between the dentinal tubules, surrounded by highly mineralised peritubular dentin. The number and the diameter of the tubules are increasing towards the pulp chamber. In addition, during cavity preparation a smear layer is formed, which covers the dentin surface, and penetrates the tubules, forming a smear plug. Adhesive systems were initially used without removing the smear layer, but this led to insufficient bond strength (C.A. MITCHELL [8], M. IONAS \& al [9]).

The etch and rinse systems are based on the removal of the smear layer, whilst the new generation of self-etch systems are modifying only the smear layer (E.L. PASHLEY \& al [4]).

Nowadays it is accepted the fact that although dentinal tubules are involved in the formation of micromechanical attachment, the chemical characteristics of the surface also play an important role (J.F. MCCABE and A.W.G. WALLS [6]).

The question often arises whether to etch previously and to use the adhesive in single or double layer. The aim of this study was to test a microhybrid composite by investigating the shear bond strengths of two self-etch adhesive systems on dentin surface in various applications.

\section{Materials and Methods}

In this experimental in vitro study 40 sound human teeth, extracted for orthodontic reasons, were used. The teeth were stored in artificial saliva containing thymol until measurements were performed. The teeth were divided in two equal groups, according to the two self-etch adhesive system, then divided into three further subgroups, according to the different application methods.

In order to obtain the flat dentin surfaces, enamel was removed with a diamond bur, under standardized conditions. After the enamel was removed, the smear layer was created on the wet dentin, by using a 180-grit carbide paper for 15 seconds. Then the surfaces were washed and slightly dried.

The adhesive systems used in the study were the Gluma Bond Universal (Heraeus Kulzer) and the Futurabond DC (VOCO). One reason for the choice of test materials was that, according to the manufacturers' guide, these two adhesive systems may be applied either with etch and rinse or self-etch techniques. The manufacturers' instructions are the same for both materials and include optional total or selective etching. Based on that, different protocols were followed in the three subgroups. The methods used for application of adhesives in the created groups are shown in Table 1.

Table 1. Steps of adhesive application on dentin surfaces

\begin{tabular}{|c|c|c|}
\hline Subgroup 1 & Subgroup 2 & Subgroup 3 \\
\hline$>$ gently air dry & $>$ gently air dry & $>$ etching for 15 sec $(X$-acid, Schulzer $)$ \\
\hline$>$ applying adhesive for $20 \mathrm{sec}$ & $>$ applying $1^{\text {st }}$ layer of adhesive for $20 \mathrm{sec}$ & $>$ rinse \\
\hline$>$ air dry for $5 \mathrm{sec}$ & $>$ air dry for $5 \mathrm{sec}$ & $>$ gently air dry \\
\hline$>$ light-cure for $10 \mathrm{sec}$ & $\begin{array}{l}>\text { applying } 2^{\text {nd }} \text { layer of adhesive for } 20 \mathrm{sec} \\
>\text { air dry for } 5 \mathrm{sec} \\
>\text { light-cure for } 10 \mathrm{sec}\end{array}$ & $\begin{array}{l}>\text { applying adhesive for } 20 \mathrm{sec} \\
>\text { air dry for } 5 \mathrm{sec} \\
\quad>\text { light-cure for } 10 \mathrm{sec}\end{array}$ \\
\hline
\end{tabular}


Prior to the light-cure step a plastic cylinder was placed on the surface of each sample. After light-curing the adhesive, the plastic cylinder was filled with microhybrid composite resin Super-Cor, Spofa Dental (Table 2). A metal hook was placed into the composite, then the material was light-cured according to the manufacturer's instructions. Using a scalpel, the plastic cylinder was removed. The resulting composite cylinder had a diameter of $2.8 \mathrm{~mm}$, and a height of $4.8 \mathrm{~mm}$. The obtained samples were suitable for the shear bond test (Figure 1).

Table 2. The polymer-based composite material used in the study

\begin{tabular}{|c|c|}
\hline Name & Super-Cor \\
\hline Manufacturer & Spofa Dental, Czech Republic \\
\hline Type & Universal microhybrid light-curing dental restorative material \\
\hline Composition & $\begin{array}{l}\text { Based on methacrylates and a variety of silica-based glass fillers; } \\
\qquad \begin{array}{c}\text { Filler volume } 59 \% ; \\
\text { Particle size: } 0.6 \mu \mathrm{m} ;\end{array} \\
\text { Main resin component: Bisphenol A glycidyldimethacrylate }\end{array}$ \\
\hline & Bis-GMA \\
\hline Health risc component & Hexamethylene diacrylate $2-3 \%$ \\
\hline
\end{tabular}

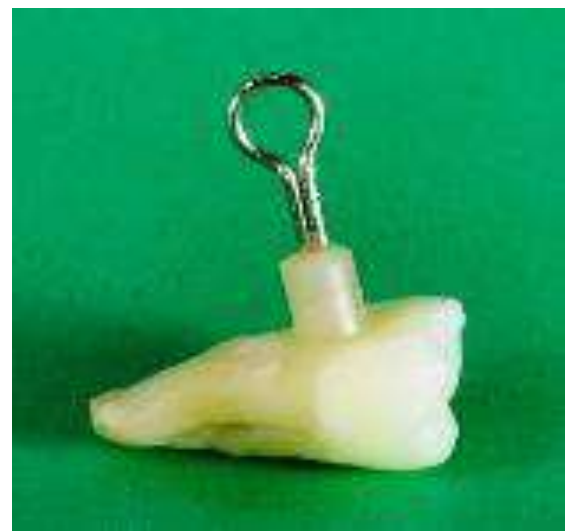

Figure 1. A prepared sample for testing shear bond strengths of composite to dentin.

The samples were attached by the metal hook to the tester machine (AXIS), in a manner that the axis of the shear force stab perpendicular on the surface. The shear force was gradually increased until the composite cylinder was dislodged from the dentin surface. The tester machine recorded the maximum force. Using the recorded data, the microshear bond strength was calculated using the following formula:

$$
R_{m}=\frac{F_{m}}{s_{0}}
$$

$\mathrm{R}_{\mathrm{m}}$ is the microshear bond, $\mathrm{F}_{\mathrm{m}}$ is the maximum force during the test and $s_{0}$ is the cross-sectional area of the composite. Data were collected in Excel tables and statistical analysis was performed by independent t-tests (GraphPad InStat) at $p<0.05$ significance level.

\section{Results and Discussions}

The microshear bond strengths average values obtained for the two adhesive systems and different application methods are shown in Table 2.

In the case of Gluma Bond Universal adhesive the double layer technique showed a significantly higher shear bond strengths, than using it in single layer $(p=0.04)$. There was no statistically significant difference between the single layer and double layer application of Futurabond $\mathrm{U}$ adhesive $(p>0.05)$. When preliminary acid etching was applied there were no significant differences in the shear bond strength values, in none of the used adhesives $(p>0.05)$. The smallest mean values were observed in the single layer application technique, for both of the studied adhesive systems (Table 3 ). 
Table 3. Mean bond strengths values and standard deviations for tested adhesives and different application methods

\begin{tabular}{|c|c|c|}
\hline & Gluma Bond Universal & Futurabond $U$ \\
\hline Single layer application & $7.16 \pm 1.83 \mathrm{MPa}$ & $6.41 \pm 2.89 \mathrm{MPa}$ \\
\hline Double layer application & $13.66 \pm 2.72 \mathrm{MPa}$ & $7.71 \pm 2.67 \mathrm{MPa}$ \\
\hline Preliminary acid etching & $11.28 \pm 2.17 \mathrm{MPa}$ & $9.48 \pm 3.07 \mathrm{MPa}$ \\
\hline
\end{tabular}

Studies published in the scientific literature focus on shear forces and on shear bond strength. In our study we preferred to investigate the shear bond strength, because the force is distributed more evenly than in case of shear forces. The higher the concentrated forces are at a given point, the higher is the incidence of an earlier fracture, producing therefore lower values. Microshear tests are used to measure the bond strength of composites' dentin-polymer interfaces (N.H. FELEMBAN and M.I. EBRAHIM [3], W.G. MCDONOUGH \& al [10]).

Fractures during the sample preparations are more common, and they can lead to creating a load, that provides lower strength data. In different studies the sample preparation, storage conditions and measuring methods might be various, resulting great differences in reported data, making the comparison of results difficult (R.L. SAKAGUCHI and J.M. POWERS [11]).

Studies on self-etch adhesive systems' shear bond strength have shown that using the double application technique provides significantly higher values than those applied in a single layer (N.H. FELEMBAN and M.I. EBRAHIM [3], D. ELKASSAS \& al [12], M. TASCHNER $\&$ al [13]). In the present study Gluma Bond Universal also showed significantly higher values when applied in two layers $(p=0.04)$. Futurabond $U$ also showed increased shear bond strength, but this difference was not statistically significant $(p>0.05)$.

The results of a study (K. MARTHA \& al [14]) where a $37 \%$ phosphoric acid was used for etching the enamel, presented pronounced etching pattern, in comparison with etching with a self-etching primer which determined a moderate demineralization of the enamel surface.

In another study the authors (O. BOTOACA \& al [15]) observed high tensile strength of adhesive systems.

Researchers concluded that in vitro studies are necessary to evaluate the adhesion of self-etch adhesives to dental hard tissues (A. PORUMB \& al [16]).

Another study examined the effect of the different surface preparation methods. Changes in microshear bond strength were analysed in preliminary etched surfaces and self-etching adhesive system. There were reported no significant differences between the two groups
(A. WAGNER \& al [17]) in agreement with the results of the present study.

The efficiency of adhesion to dentin surfaces can be achieved by other methods, for which our study can be further extended. Some studies investigate the effect of sandblasting on the shear bond strengths to the dentin surface. The mechanical treatment increases the roughness of the surface and increases the adhesion surface as well. Aluminium oxide powder (with $50 \mu \mathrm{m}$ particles) may be suitable for this technique. In one of these studies significant increase of shear bond strength was observed on surfaces treated with aluminium oxide particles (M. D’AMARIO \& al [18]).

Another study reports similar results when the surface was treated with bicarbonate sodium (B.G. DA SILVA SUTIL and A.H. SUSIN [19]). Electron microscopic findings showed that the smear layer is removed by both methods (acid etching and sandblasting), but there is a significant difference regarding the surface's microstructure. While using acid etching the result was a smoother surface than using sandblasting, however the original dentin tubules' diameter and the amount of the inter-tubular dentin was preserved in case of sandblasting (C.F. RAFAEL \& al [20]).

Nowadays there is an increasing interest for implants and laser use in dentistry (A. POLL \& al [21], A. POLL \& al [22], V. NIMIGEAN \& al [23], V. NIMIGEAN \& al [24]). Laser can be used to create a surface with micromechanical retentions, but it is not a substitute for the acid etching step. In vitro studies showed that the degree of adhesion was found to be lower, than in case of acid etched dentin surface (H. ALAGHEHMAND \& al. [25]). We intend to extend our research to these alternative methods for increasing the shear bond strengths of composite resin restorative materials to dentin surface. However, in vitro experiments may provide useful data, in vivo studies could present the clinical conditions (M.J. TUCULINA \& al [26]).

Resin-based composite materials are the most widely used tooth-coloured restorative materials in dentistry and are commonly referred to as composites. The resin forms the matrix of the composite and the coupling agent is binding the filler particles (R. VAN NOORT [27]). Main areas of development in composites were with respect to 
their composition and polymerisation technique. Recent publications revealed favourable properties of composites obtained by smaller filler particle size (A. PORUMB \& al [16]) and novel matrix composition (T.M. ELSHAZLY \& al [28]).

Microhybrid composites are the most widely used aesthetic restorative materials in our region. The wear resistance of these composites was investigated under different experimental conditions (A. BORS \& al [29], A. BORS \& al [30], C. DUDAS \& al [31]). The microhybrid composite resin used in the present study was selected because it was also tested in our previous in vitro experiment which revealed its high wear resistance (C. DUDAS \& al [31]).

The results have to be interpreted within the limitation of the experimental design applied in current in vitro study, however the findings could have a clinical interest.

\section{Conclusions}

In experimental conditions the shear bond strength of tested microhybrid composite resin to dentin increases when double-layer application of self-etch adhesive is used, however this improvement is adhesive dependent. The use of optional preliminary acid etching does not improve significantly the bond strength of composite resin to dentin.

\section{Conflict of Interests} interests.

The authors declare that they have no conflict of

\section{Author contribution}

Author \# 1 (BERNADETTE KEREKES-MATHE) and author \# 6 (VICTOR NIMIGEAN) have equal contributions to this paper and thus are main authors.

\section{References}

1. C.S. PFEIFER. Polymer-Based Direct Filling Materials. Dent Clin North Am, 61(4), 733-750 (2017).

2. A. BORS, M. SZEKELY, C. MOLNAR-VARLAM. Tehnici adezive moderne în medicina dentară. Ed. University Press, Târgu Mureș, 32-58 (2015).

3. N.H. FELEMBAN, M.I. EBRAHIM. Effect of adhesive layers on microshear bond strength of nanocomposite resin to dentin. J Clin Exp Dent, 9(2), 86-90 (2017).

4. E.L. PASHLEY, K.A. AGEE, D.H. PASHLEY, F.R. TAY. Effects of one versus two applications of an unfilled, all-in-one adhesive on dentine bonding. J Dent, 30(2-3), 83-90 (2002).
5. A.N. CHOI, J.H. LEE, S.A. SON, K.H. JUNG, Y.H. KWON, J.K. PARKET. Effect of Dentin Wetness on the Bond Strength of Universal Adhesives. Materials (Basel), 10(11), 1224 (2017), DOI: $10.3390 /$ ma10111224.

6. J.F. MCCABE, A.W.G. WALLS. Applied Dental Materials, 9th Ed., Blackwell Publishing Ltd, 23-25, 229-233 (2008).

7. A.D. LOGUERCIO, S.K. MOURA, A. PELLIZZARO, K. DAL-BIANCO. Durability of Enamel Bonding Using Two-step Self-etch Systems on Ground and Unground Enamel. Oper Dent, 33(1), 79-88 (2008).

8. C.A. MITCHELL. Dental Materials in Operative Dentistry. Quintessence Publishing Co. Ltd., London, 56-58 (2008).

9. M. IONAS, M. MOLDOVAN, M. TRIF, C. SAROSI, C. ALB, T. IONAS, G.L. POPESCU. Qualitative Evaluation by Means of SEM on the Qualities of the Hybrid Layer Formed by an Experimental Self Etching Adhesive. Rev Chim (Bucharest), 62(5), 514517 (2011).

10. W.G. MCDONOUGH, J.M. ANTONUCCI, J. HE, Y. SHIMADA, M.Y.M. CHIANG, G.E. SCHUMACHER, C.R. SCHULTHEISZ. A microshear test to measure bond strengths of dentin-polymer interfaces. Biomater, 23(17), 3603-3608 (2002).

11. R.L. SAKAGUCHI, J.M. POWERS. Craig's Restorative Dental Materials, 13th Ed., Mosby Inc, 97-98, 330-332 (2012).

12. D. ELKASSAS, H.A. TAHER, N. ELSAHN, R. HAFEZ, W. EL-BADRAWY. Effect of the number of applications of acetone-based adhesives on microtensile bond strength and the hybrid layer. Oper Dent, 34(6), 688-696 (2009).

13. M. TASCHNER, M. KUMMERLING, U. LOHBAUER, L. BRESCHI, A. PETSCHELT, R. FRANKENBERGER. Effect of double-layer application on dentin bond durability of one-step self-etch adhesives. Oper Dent, 39(4), 416-426 (2014).

14. K. MARTHA, A. OGOdescU, C. BICA, E. OGODESCU, I. ZETU. Comparative SEM analysis of the effect of acidic monomers and phosphoric acids on dental enamel. Rev Chim (Bucharest), 64(8), 875-879 (2013).

15. O. BOTOACA, E.S. BECHIR, R.M. COMANEANU, S. COMAN, M. TARCOLEA, L. DRAGUS. Preliminary Study on the Tensile Strength of Some Adhesive Materials Used to Luting Brackets. Rev Chim (Bucharest), 70(1), 84-86 (2019).

16. A. PORUMB, A, ALMASI, L. TODOR, C.A. RATIU, G. CIAVOI, P.C. TODOR, S.A. TODOR, M.N. MATEI, C. ROMANEC, R.I. MATEI. In vitro Study 
of the Structure and Adhesive Interface in Direct Restorations with Experimental Nanocomposite Materials and Adhesive Systems. Mater Plast, 55(4), 620-625 (2018).

17. WAGNER, M. WENDLER, A. PETSCHELT, R. BELLI, U. LOHBAUER. Bonding performance of universal adhesives in different etching modes. J Dent, 42(7), 800-807 (2014).

18. M. D'AMARIO, C. PICCIONI, S. DI CARLO, F. DE ANGELIS, S. CARUSO, M. CAPOGRECO. Effect of Airborne Particle Abrasion on Microtensile Bond Strength of Total-Etch Adhesives to Human Dentin. Biomed Res Int, 2017, DOI: 10.1155/2017/2432536.

19. B.G. DA SILVA SUTIL, A.H. SUSIN. Dentin pretreatment and adhesive temperature as affecting factors on bond strength of a universal adhesive system. $J$ Appl Oral Sci, 25(5), 533-540 (2017).

20. C.F. RAFAEL, V. QUINELATO, C.S. MORSCH, G. DEDEUS, C.M. REIS. Morphological Analysis of Dentin Surface after Conditioning with Two Different methods: Chemical and Mechanical. J Contemp Dent Pract, 17(1), 58-62 (2016).

21. A. POLL, V.R. NIMIGEAN, D. BADitA, R.A. BALACEANU, S.C. CISMAS, P. PERLEA, S.A. MORARU, V. NIMIGEAN. In vivo experimental model for the evaluation of dental implant integration. Rom Biotechnol Lett, 23(2), 13505-13510 (2018).

22. POLL, C.A. MINCULESCU, V.R. NIMIGEAN, D. BADITA, R.A. BALACEANU, D.L. PAUN, S.A. MORARU, V. NIMIGEAN. Experimental model for the study of autogenous mandibular bone grafts integration. Rom Biotechnol Lett, 23(3), 13681-13689 (2018).

23. V. NIMIGEAN, V.R. NIMIGEAN, D.I. SALAVASTRU, S. MORARU, L. BUTINCU, R.V. IVASCU, A. POLL. Immunohistological aspects of the tissues around dental implants. Conference: $5^{\text {th }}$ Congress of the World-Federation-for-LaserDentistry/6th International Conference on Lasers in Medicine Location: Bucharest, Romania, 07-09.05.
2015. Book Series: Proceedings of SPIE, vol. 9670, Published: 2016. DOI:10.1117/12.2197741.

24. V. NIMIGEAN, A. POLL, V.R. NIMIGEAN, S.A. MORARU, D.G. BADITA, D.L. PAUN. The Routine and Specialised Staining for the Histologic Evaluation of Autogenous Mandibular Bone Grafts. An experimental study. Rev Chim (Bucharest), 69(5), 11061109 (2018)

25. H. ALAGHEHMAND, F.N. NASROLLAH, H. NOKHBATOLFOGHAHAEI, R. FEKRAZAD. An in vitro comparison of the bond strength of composite to superficial and deep dentin, treated with Er:YAG laser irradiation or acid-etching. J Lasers Med Sci, 7(3), 167-171 (2016).

26. M.J. TUCULINA, M. RAESCU, I.T. DASCALU, M. POPESCU, C.F. ANDREESCU, C. DAGUCI, C.N. CUMPATA, V.R. NIMIGEAN, I.M. BANITA. Indirect pulp capping in young patients: immunohistological study of pulp-dentin complex. Rom J Morphol Embryol, 54(4), 1081-1086 (2013).

27. R. VAN NOORT. Introduction to Dental Materials 3rd Ed, Mosby Elsevier Limited, Edinburgh, 99 (2007).

28. T.M. ELSHAZLY, C. BOURAUEL, D.I. SHERIEF, D.I. EL-KORASHY. Evaluation of Two Resin Composites Having Different Matrix Composition. Dent J, 8(3), 76, (2020), DOI: 10.3390/dj8030076.

29. A. BORS, C. MOLNAR-VARLAM, O. BIRTA, M. SZEKELY. Erosive wear resistance of direct restorative materials - an in vitro study. Int $\mathrm{J} \mathrm{Med}$ Dent, 18(4), 278-285 (2014).

30. BORS, I. ANTONIAC, C. COTRUT, A. ANTONIAC, M. SZEKELY. Surface analysis of contemporary aesthetic dental filling materials after storage in erosive solutions. Mater Plast, 53(4), 607-611 (2016).

31. DUDAS, M. SZEKELY, M.H. GABOR., L. JAKABFARKAS, K. DORNER, V.R. NIMIGEAN, V. NIMIGEAN, C. MOLNAR-VARLAM, B. KEREKESMATHE. Effect of tooth brushing on wear of microhybrid composites - In vitro experiment. Mater Plast, 56(3), 583-587 (2019). 